\title{
Neurological manifestations of COVID-19 infection: an umbrella review
}

\author{
Samad Shams Vahdati ${ }^{1}$, Alireza Ala ${ }^{1}$, Dara Rahmanpour ${ }^{2}$, Elyar Sadeghi-Hokmabadi ${ }^{3}$ and Fateme Tahmasbi² ${ }^{*}$ (D)
}

\begin{abstract}
Background: Neurological involvements of COVID-19 are one of the most reported manifestations of this infection. This study aims to systematically review the previous systematic reviews which addressed the neurological manifestations of the COVID-19 infection.

Methods: Following the Preferred Reporting Items for Systematic Review and Meta-Analysis (PRISMA) guidelines, a comprehensive search was conducted in PubMed, Embase, Scopus, Web of Science databases and Google Scholar from December 2019 to December 2020. Articles were critically screened by two independent reviewers and if met the inclusion criteria, entered the study. Assessment of methodological quality was conducted by Assessment of Multiple Systematic Reviews-2 (AMSTAR-2) tool. Statistical analysis was not applicable. From a total of 1302 studies, 308 studies were removed due to their irrelevant title and abstract. After screening the full texts, a total of 66 found to be eligible. Twenty-one studies reported general manifestations of the COVID-19, 13 studies reported cerebrovascular events, 19 olfactory and oral dysfunctions, 5 systematic reviews on Guillen-Barré syndrome (GBS) and 8 articles on the sporadic manifestations like ocular signs and symptoms. The majority of the studies were classified as critically low or low in terms of quality.

Conclusion: Despite great heterogeneity in the current literature, neurological involvements are an important extra-pulmonary aspect of the COVID-19; most commonly in the form of general manifestations like headache and olfactory disturbances. Long-term effects of this virus on the nervous system must be a research priority for future references.
\end{abstract}

Keywords: Corona virus disease 2019, COVID-19, Neurological manifestations, Neurology, Systematic review

\section{Introduction}

In December 2019, coronavirus disease 2019 (COVID19) started by an outbreak in China and soon afterwards, infected millions of people all over the world and revolutionized our whole perspective of the healthcare.

Most reported signs and symptoms of COVID-19 infection are fever, dry coughs and fatigue [1]. Nevertheless, respiratory invasions are not the only medical concern regarding this virus. According to many reports, COVID-19 has proven to be a multi-organ disorder with

\footnotetext{
*Correspondence: ftahmasbi997@gmail.com

${ }^{2}$ Student Research Committee, Tabriz University of Medical Sciences, Tabriz, Iran

Full list of author information is available at the end of the article
}

multiple extra-pulmonary manifestations, including cardiovascular, renal, gastrointestinal and neurological $[2$, 3].

The spectrum of neurological involvement of COVID19 has been a growing body of literature, ranging from simple headaches to more severe manifestations like stroke and seizures [4-6]. Considering the immediate need of evidence, there are a great number of studies published every day. It is obvious that reaching a reliable and valid source of evidence is essential for clinical decision-making and on higher levels, policy-making. Therefore, a challenging field has come into the spotlight.

A systematic review on systematic reviews, also known as an umbrella review, is a type of novel methodology which aims to summarize an extensive scope of literature 
and provide a holistic view on a specific matter. Umbrella reviews can provide the highest level of evidence and benefit both clinicians and policy-makers $[7,8]$.

To our knowledge, no publications have reported this gap. Therefore, we conducted a systematic review on the previous systematic reviews that addressed the neurological signs and symptoms of the COVID-19 infection in an attempt to classify and broaden the current literature on the matter.

\section{Methods}

This study is conducted in accordance to Preferred Reporting Items for Systematic Reviews and Meta-analysis (PRISMA) guidelines [9].

\section{Protocol and registration}

The protocol of this study is registered and approved by the Research Ethics Committee of Tabriz University of Medical Sciences. (ID: IR.TBZMED.REC.1399.984) Written consent from patients was exempted because the population of this study is previously published documents.

\section{Eligibility criteria}

Due to the extent of the academic literature on this matter, specific inclusion criteria was defined and applied; all the systematic reviews, with or without meta-analysis, which were conducted on the neurological manifestations of the SARS-CoV-2 infection from December 2019 to December 2020 was included in this umbrella review.

Exclusion criteria were as followed: (1) all the other methodology; including experimental studies, case-based studies, retrospective or prospective studies and narrative reviews; (2) studies with no report on the neurological signs and symptoms; (3) studies focused on a specific population like pregnant women, children, patients with specific conditions like cancer; (4) incomplete studies or studies with unavailable full text; (5) non-English studies and (6) animal studies.

\section{Information sources and search strategy}

A comprehensive literature search was conducted in PubMed, Embase, Scopus Web of Science and Google Scholar form December 2019 to December 2020 to identify all the relevant articles. Related keywords to the COVID-19 and neurological manifestations, including "COVID-19", "coronavirus", "SARS", "SARS-CoV-2", "neurology", "neurologic", "neurologic manifestations", "neurologic signs", "neurologic symptoms", "olfactory", "anosmia", "dysgeusia", "stroke", "cerebrovascular event". "Guillenbarre syndrome", "systematic review", "meta-analysis" and other relevant synonyms and their combination with the proper Boolean operators. The search results were imported in the reference managing software EndNote $\mathrm{X} 8$ for further analysis.

\section{Study selection process}

After the removing duplicates, the title and abstracts of the imported articles were evaluated by two independent reviewers (F.T and S.S.V). The remaining articles were then assessed through their full-text. Any sort of disagreement was dissolved by referring to a third reviewer (A.A).

\section{Assessing the quality of the systematic reviews}

Assessment of methodological quality of included studies was conducted by Assessment of Multiple Systematic Reviews-2 (AMSTAR-2) tool [10]. This tool consists of 16 questions regarding the mythological strengths of systematic review and categorizes their quality as critically low, low, moderate and high. The form is attached in Additional file 1.

\section{Data extraction}

The full texts of the included articles were carefully read and analyzed by two independent reviewers (F.T and S.S.V) in an Excel worksheet and following items were extracted: the name of the author, year of publication, country in which studies were conducted, the quality assessment according to AMSTAR-2 tool, population, types and number of the included studies, searched databases, neurological manifestations, the method of assessing the quality of included studies and main results. Any controversies among two reviewers were dissolved by referring to a third reviewer (A.A).

\section{Synthesis of results}

Considering the heterogeneity of the systematic reviews and studies that each review included, statistical analysis was neither feasible nor appropriate; therefore a narrative synthesis of the results was conducted.

\section{Results}

Study selection

From a total of 1302 studies, 476 studies remained after removing the duplicates. After screening the title and abstracts, 308 studies were removed due to their irrelevance, leaving 101 studies for the full-text screening. At last, a total of 66 studies were included in this systematic review. The process is summarized in Fig. 1. In addition, the results of quality assessment using the AMSTAR-2 tool are also presented in Fig. 2. 


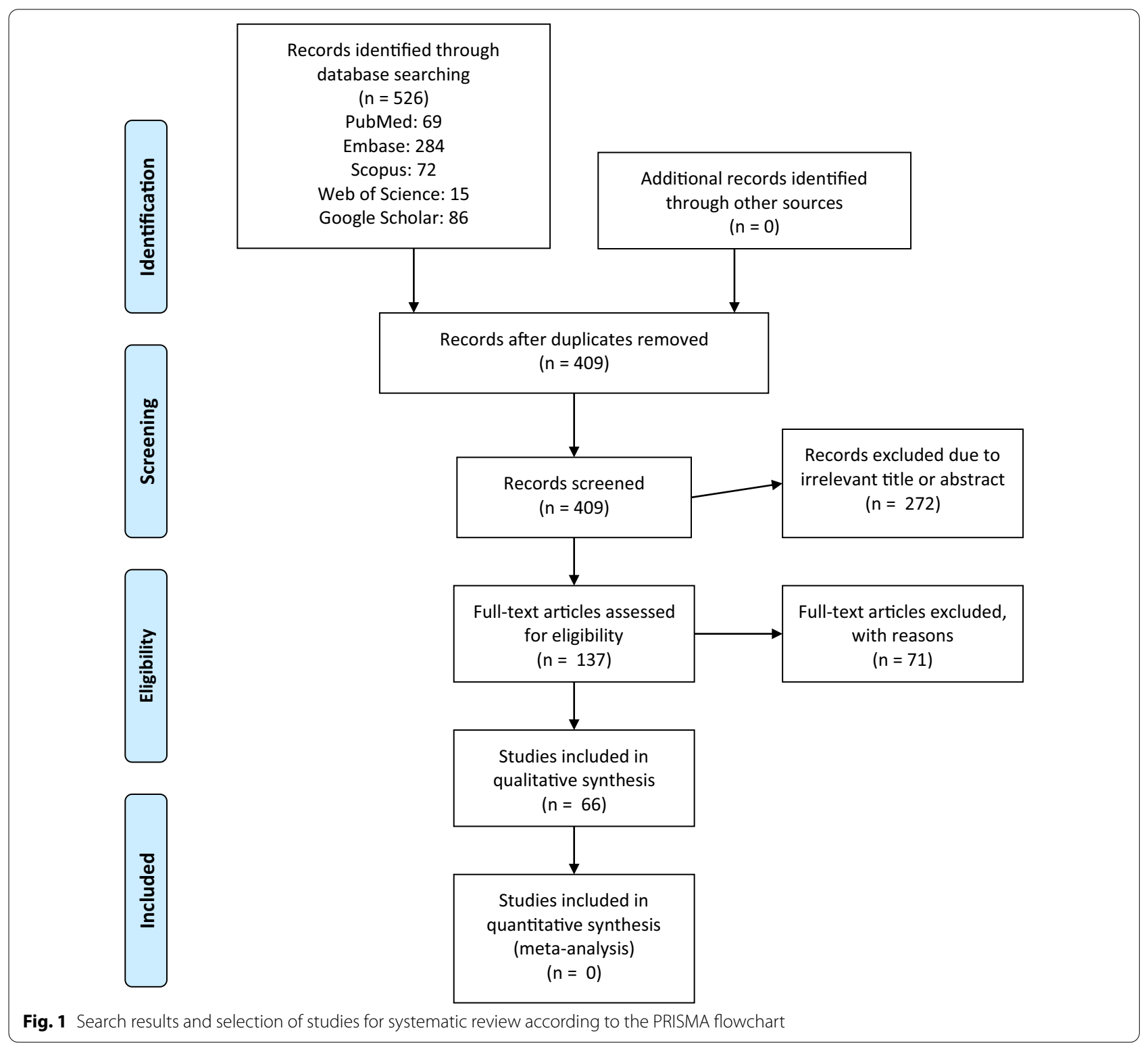

\section{Studies on general neurological manifestations}

A total of 21 studies reported neurological findings in COVID-19 patients. Nine studies conducted a metaanalysis of the included studies [11-18]. Regarding the origin of the studies, seven studies were conducted in Europe [19-25], three in Iran $[15,26,27]$ and one in each of the following countries China [18], Nepal [28], Nigeria [11], Philippines [13], India [14], Brazil [29], Indonesia [16], Singapore [12], Taiwan [17], Egypt [30], USA [31]. The number of their included studies varied from 7 to 212. Population of the studies consisted of patients with different stages of COVID-19 infection.

Different studies included a wide spectrum of neurological manifestations; some studies included muscular or musculoskeletal involvement $[11,28,31]$, several studies included cerebrovascular events [11, 12, 15-19, 21, 22, 24-29, 31]; several studies cover olfactory and gustatory dysfunctions or OGD [11, 13, 14, 17, 18, 20-26, 28, 29], dizziness was mentioned in eight studies [11, $13,14,16,17,19,21,30]$, inflammation of the brain tissue or adjacent structure like meninges was mentioned in five studies [12, 18, 23, 29, 31], impaired concussion also mentioned in five studies $[11,13,16,19,20]$.

According to one study, the most common neurological manifestations in hospitalized patients were headache and anosmia [25]. In several studies, headache continued to be described as the most common neurologic sign in COVID-19 patients $[13,19,20,26,28,30]$. It was also 


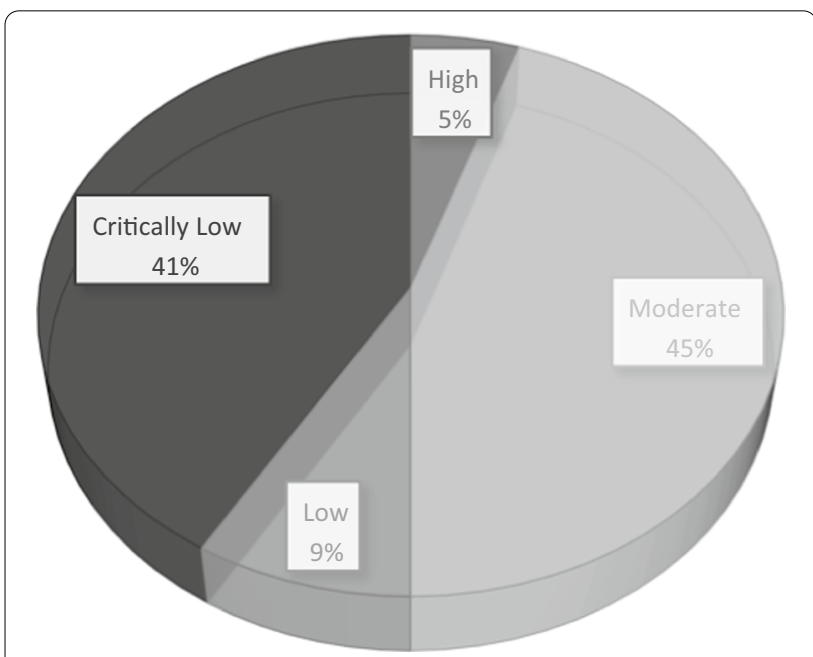

Fig. 2 The quality of included studies according to the AMSTAR-2

mentioned by other studies with different prevalence [11, $14,16,17,21]$. One study stated that stroke is the most frequent type of neurological dysfunction in COVID-19 patients with the highest mortality rate [12]. One study reported muscle injury or myalgia as the most common type of neurological disturbance [16]. Another study reported that fatigue is the most common non-specific involvement of the nervous system, alongside the anorexia, dyspnea/shortness of breath, and malaise [18]. OGD was also stated as the most common type of neurologic involvement by five studies [11, 14, 17, 22, 24].

Further information is presented in Table 1.

\section{Studies on cerebrovascular accidents}

A total of 13 studies were included in this systematic reviews. Six studies conducted meta-analysis [32-37], one study was a cohort plus a systematic review [38] and one study was the combination of a narrative review and systematic one [39]. Five studies were conducted in Europe [34, 38-40], two in USA [35, 41], and one in each following countries; Colombia [42], South Korea [43], Malaysia [32], India [44], Canada [33] and Singapore [37]. The population of each study was the COVID-19 patients with a form of cerebrovascular accident and different forms of stroke. Two studies did not report the type of articles included in the study $[33,43]$.

The severity of the infection was mentioned several times across studies, stating the fact that the more severe the infection becomes, the higher the risk of cerebrovascular events, including strokes [32, 36, 38, 40].

The onset of the stroke was evaluated by two studies; one provided evidence supporting a possible trend between the severity of the COVID-19 infection and the temporality of stroke; meaning that mild infection is associated with early onset and severe infection is associated with late-onset stroke [42]. This evidence was supported by another study which suggested the Neutrophil-Lymphocyte Ratio (NLR) before hospitalization is positively correlated to the duration of the features of acute ischemic stroke (AIS) [40].

The mortality rates among these patients were also assessed by several studies, one study reported that COVID-19 infection is associated with higher mortality rates in stroke patients [44]. The other study indicated that the mortality of stroke in COVID-19 patients is associated with the age, comorbidities and the severity of the infection as stated [33]. Furthermore, one study suggested that stroke can be a prognostic factor and an indicator of the severity of the infection [32].

Concurring the aforementioned findings, another study stated that COVID-19 infection is associated with an increased risk of ischemic stroke, especially cryptogenic type; in addition to an increased risk of mortality [34]. While two studies mentioned ischemic stroke as the most common type of stroke among infected patients [39, 43]. A number of studies investigated the possible risks which were associated with stroke occurrence in COVID-19 infection-age, presence of other comorbidities or stroke risk factors including a history of cerebrovascular disorders, hypertension, hyperlipidemia or diabetes $[33,36$, 41].

Additional information of these studies is provided in Table 2.

\section{Studies on olfactory and oral dysfunction}

A total of 19 systematic reviews were included regarding olfactory and gustatory dysfunction (OGD) in COVID19 patients with different severity of the infection, but in some cases the diagnosis of COVID-19 was not finalized. In addition, the population of one study was consisted of health-care workers [45]. Regarding the methodology, meta-analysis was conducted in 10 studies [46-55] and one study was a cohort plus a systematic review of literature [56]. The origins of the studies were as followed: four in UK $[45-47,57]$, three in Italy $[54,58,59]$, two in USA $[49,60]$, two in China $[53,56]$ and one in each Brazil [61], United Arab Emirates [62], Thailand [48], Nigeria [55], Iran [52], Australia [50], Singapore [51] and Greece [63].

All of the included studies agreed on the positive correlation of the OGD and COVID-19 infection. One study suggested that the olfactory dysfunction might be the only COVID-19 infection in some cases [56]. The other studies provided evidence for the possible fact that the OGD might be the very first manifestation of the infection $[53,59,60]$.

One study exclusively stated that OGD has a higher prevalence in female and younger patients [57]. 


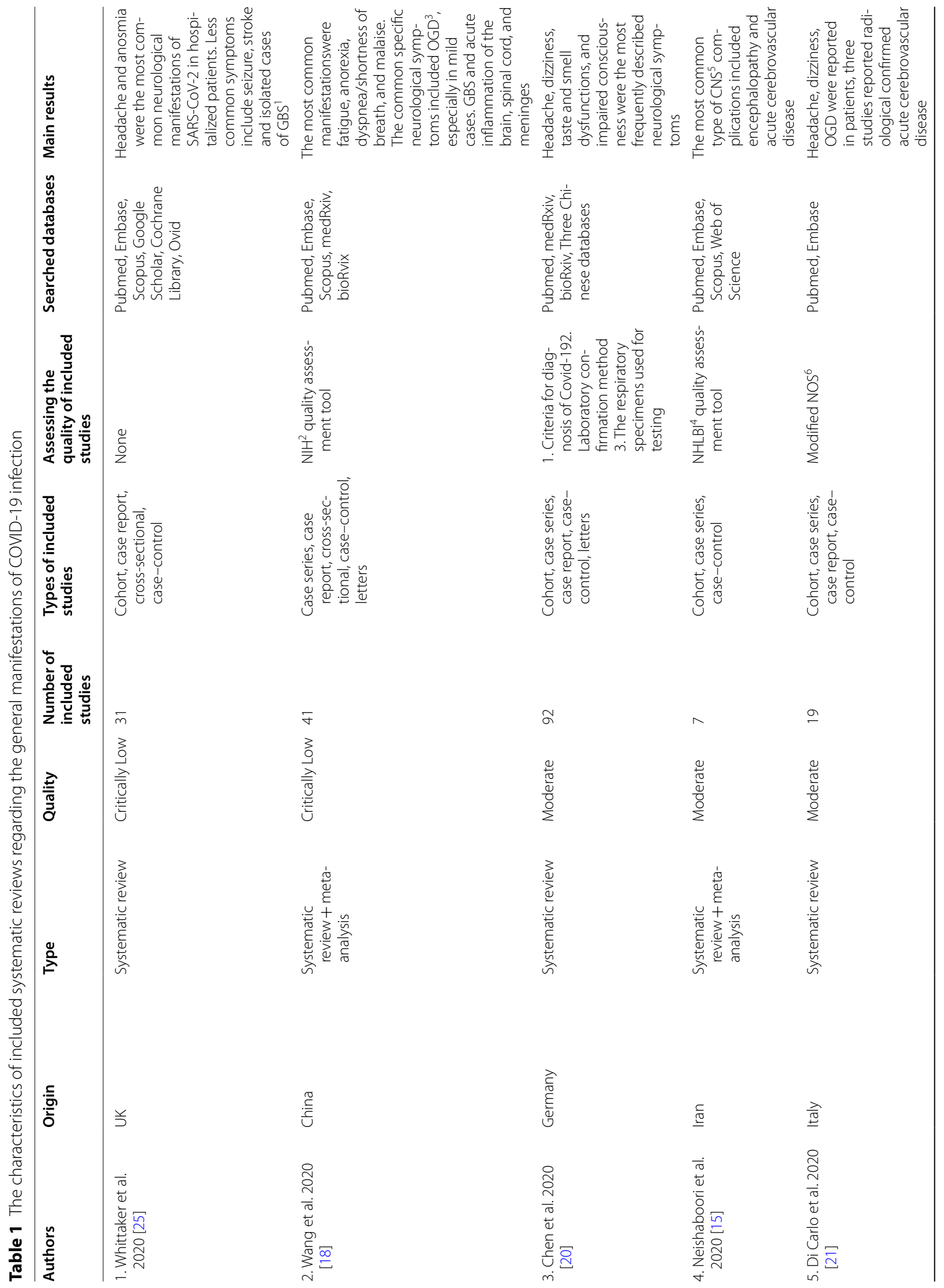




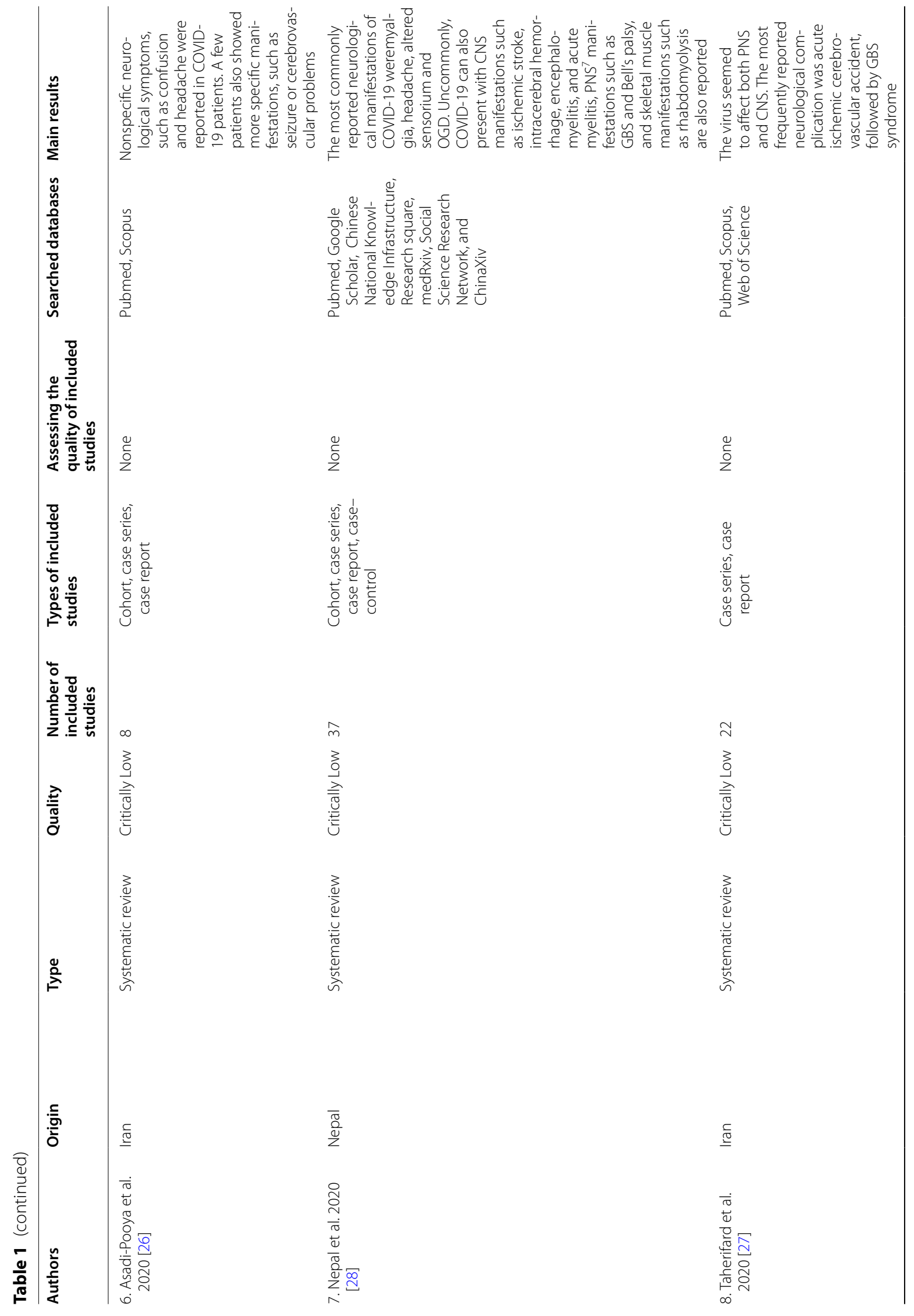




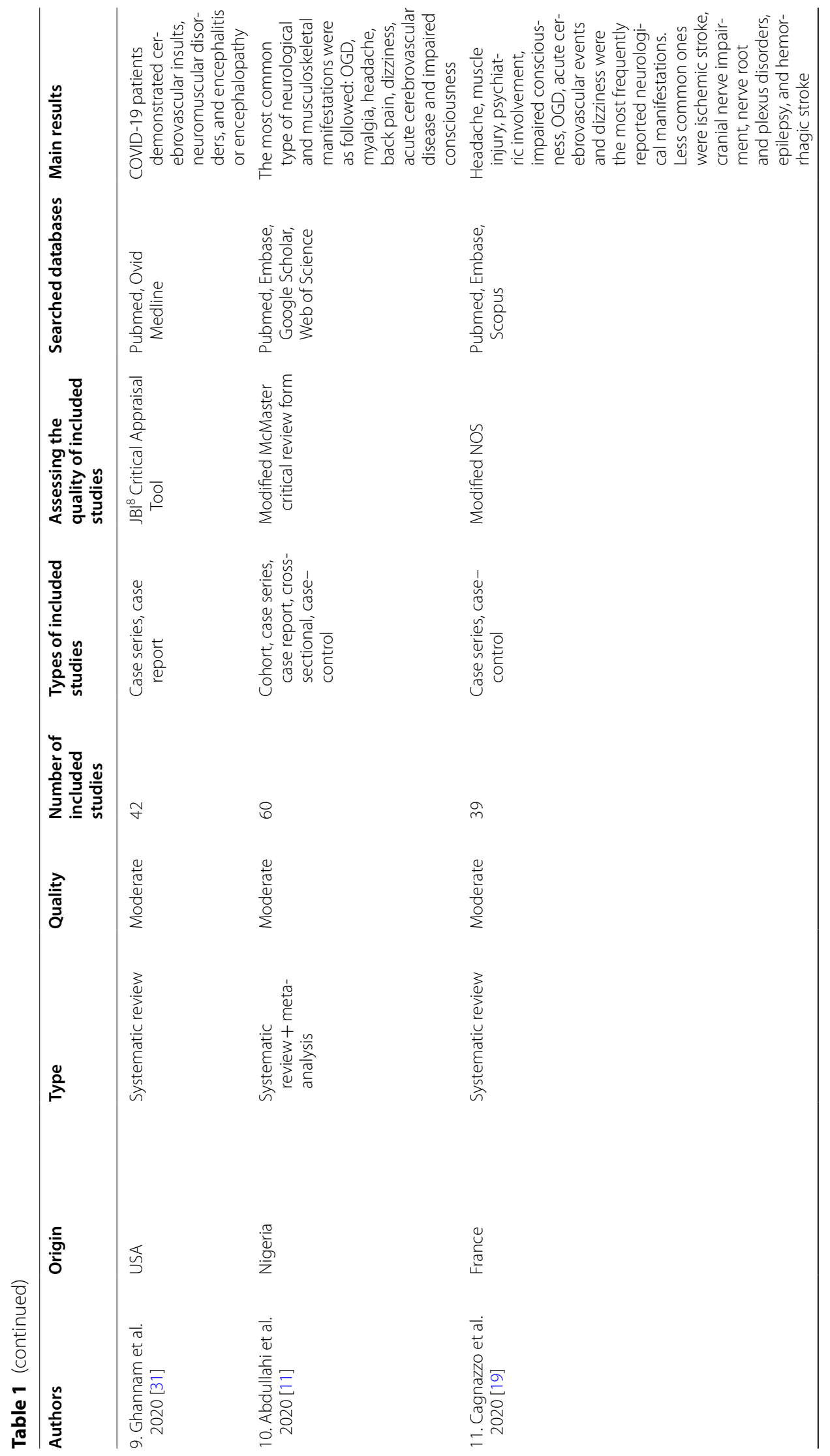




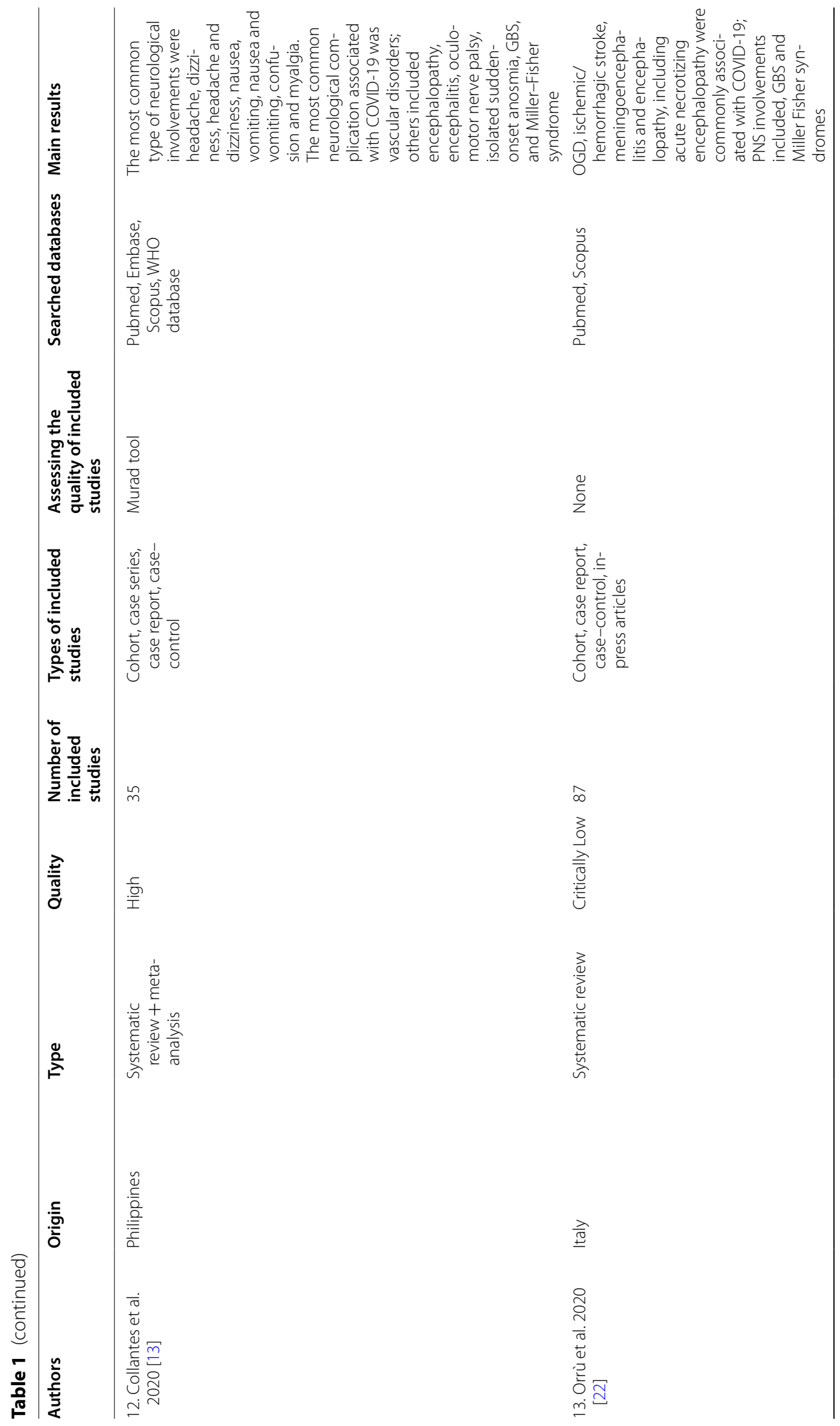




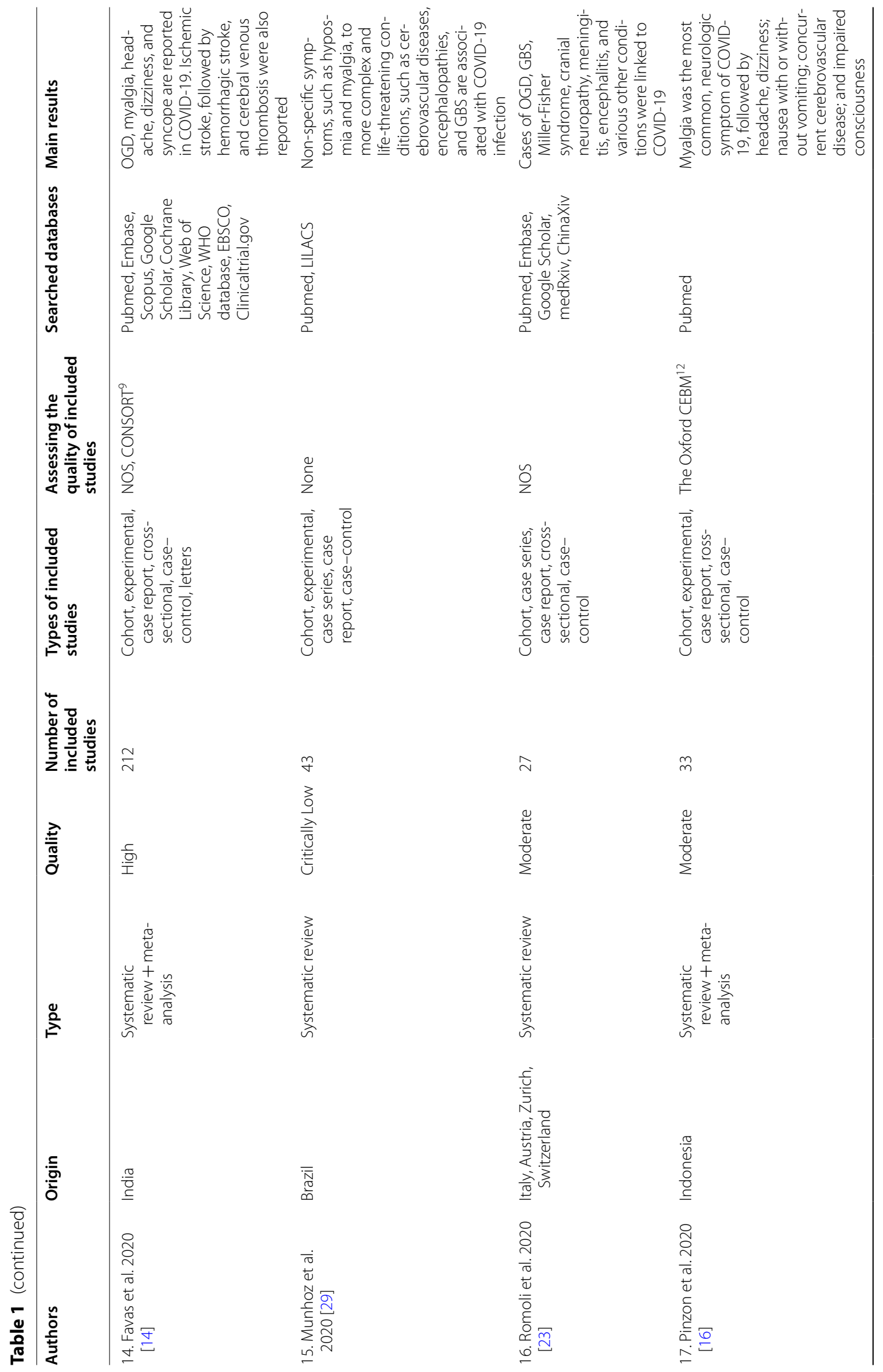




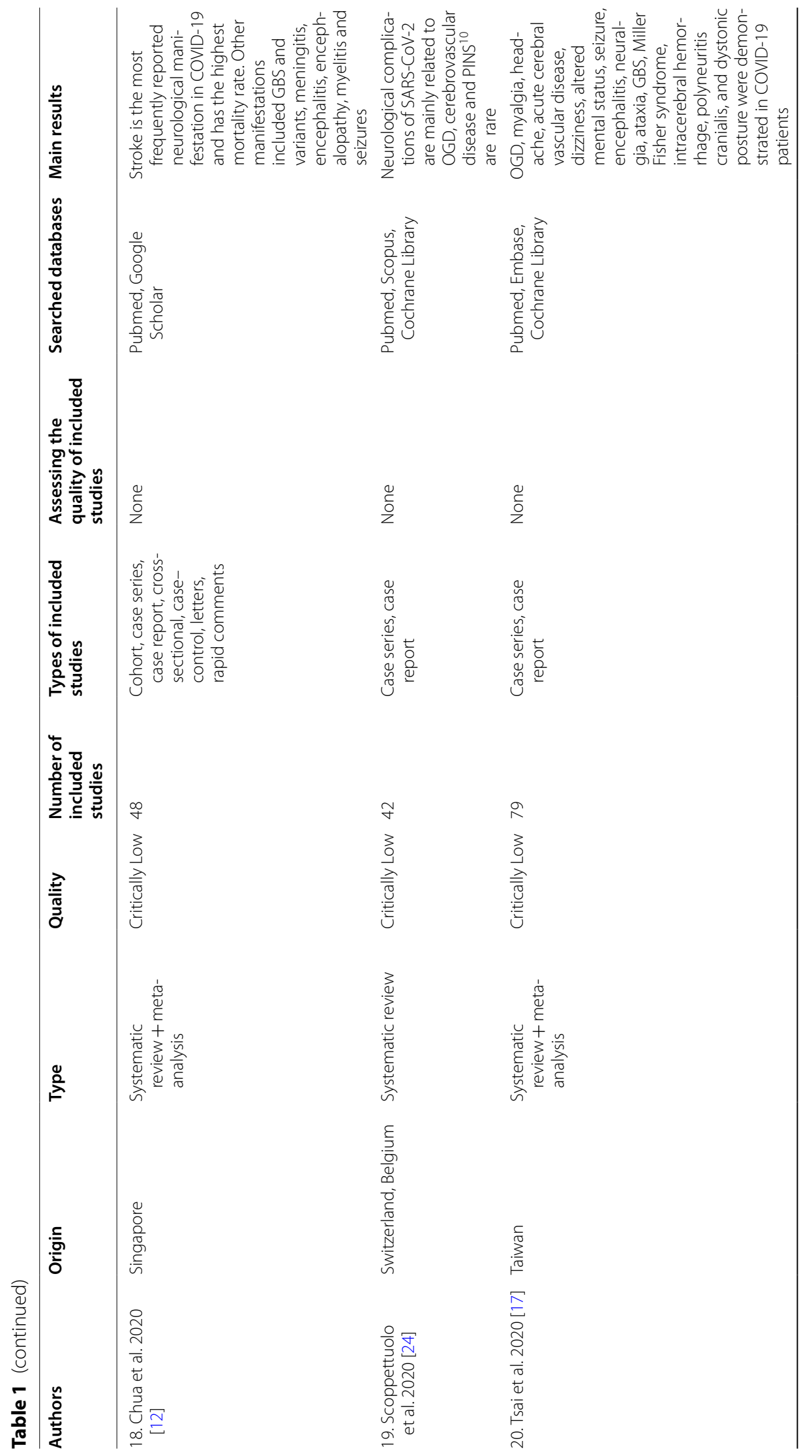




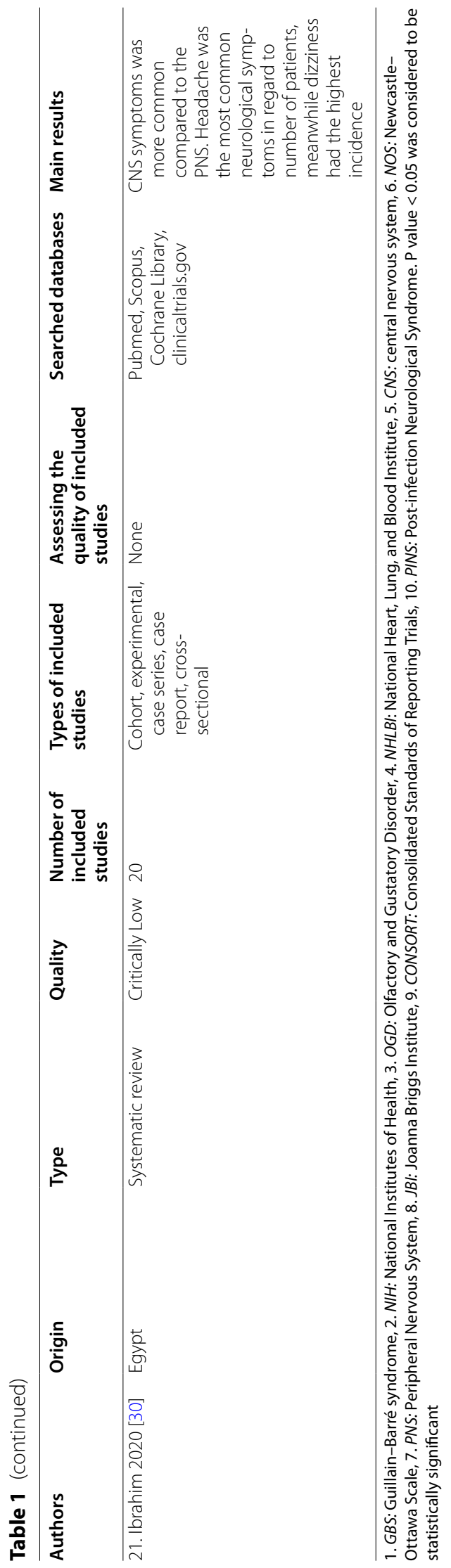




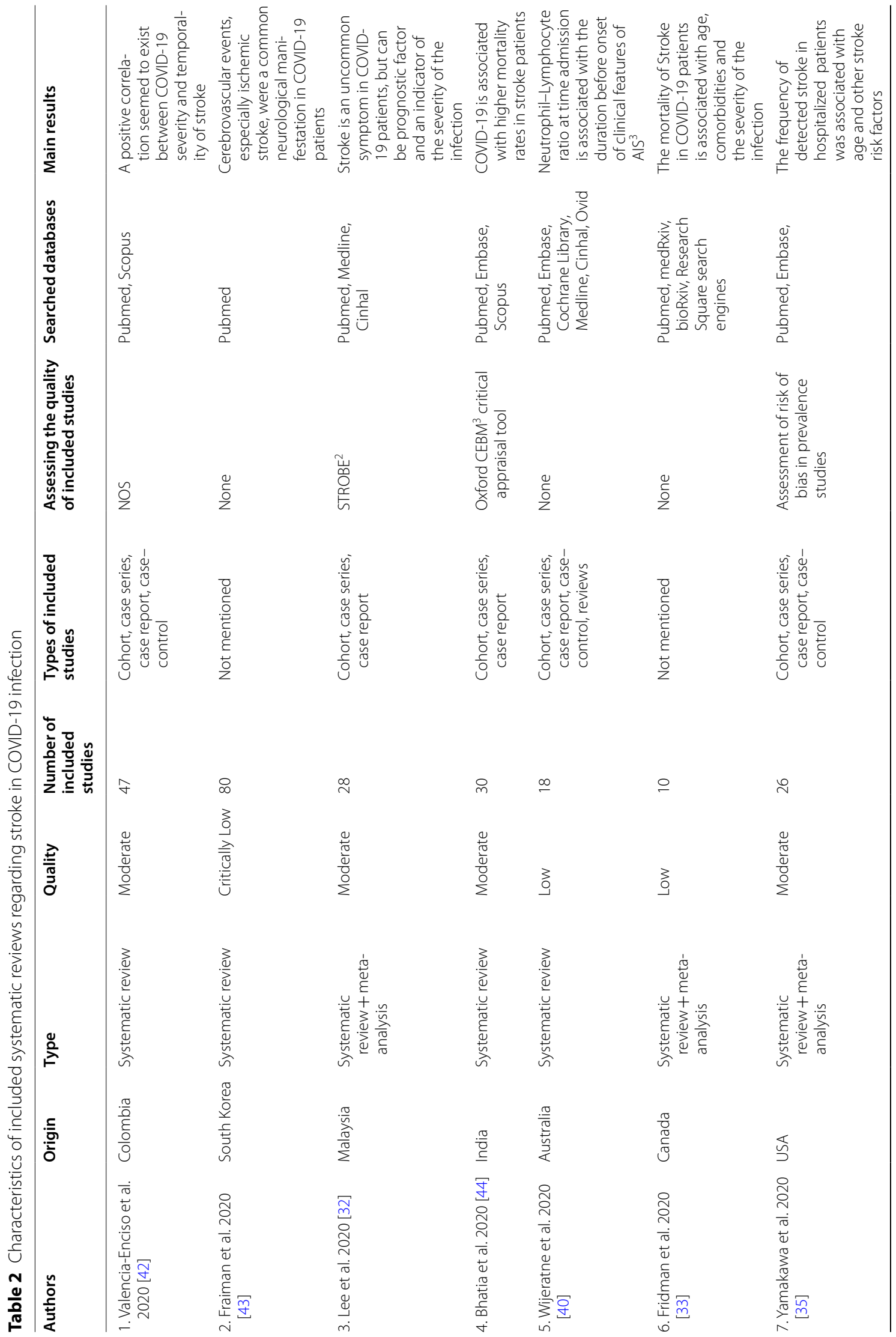




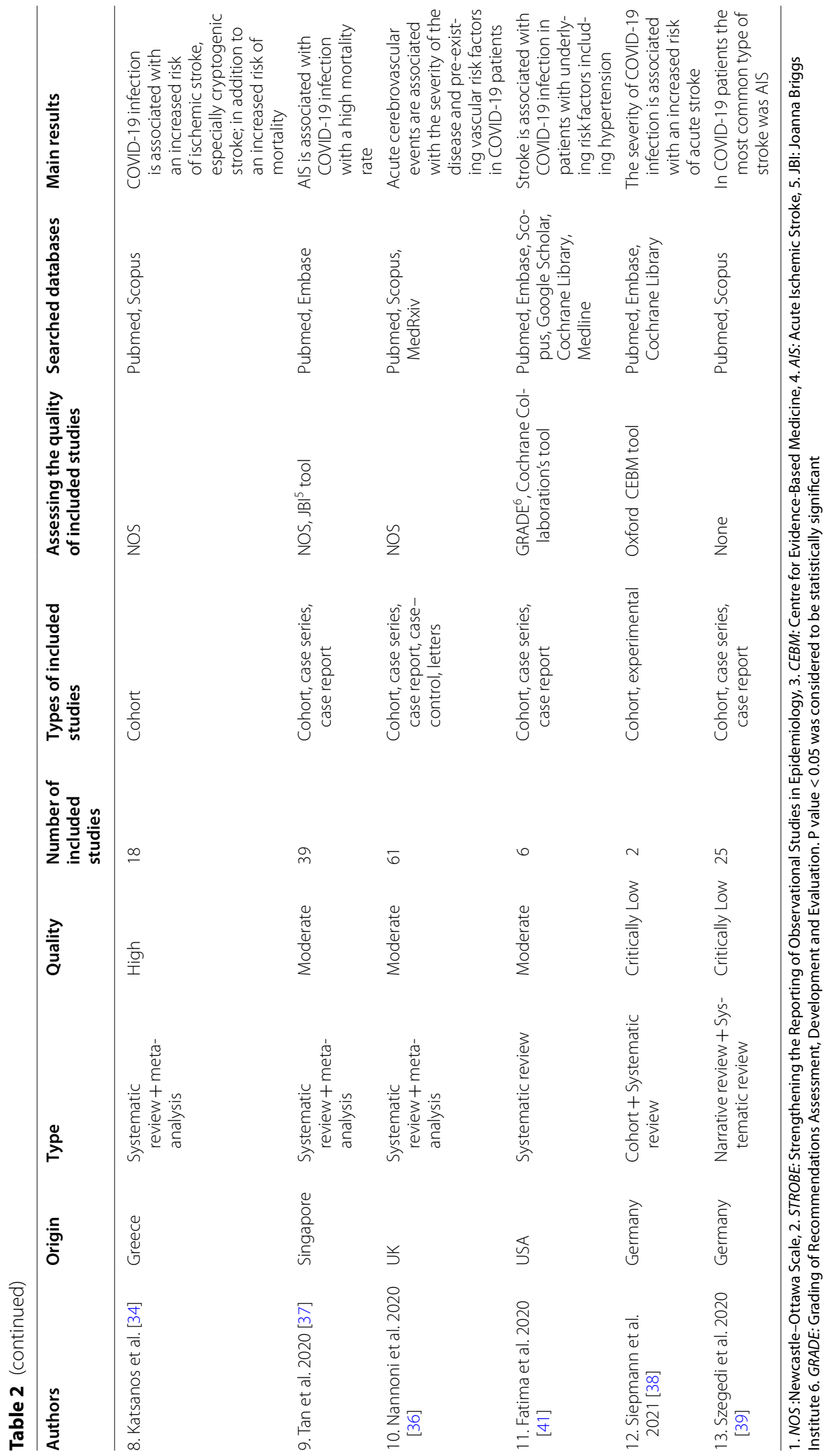


Moreover, one study suggested that the presence of other respiratory infections might lead to more severe cases on COVID-19-related anosmia [63].

The relationship between the severity of the infection and OGD was not conclusively investigated by the included studies, but in some of them was reported as the secondary outcome; for instance, one study demonstrated that anosmia is more frequent in non-hospitalized COVID-19 patients than in hospitalized [54]. Furthermore, in one study OGD symptoms were reported in both ambulatory and hospitalized patients and mild-tosevere cases of COVID-19 patients [62]. Corroborating these statements, one study claimed that OGD should be considered as a clinical manifestation of the COVID-19 infection even in mild cases [61]. Finally, the other study evinced that OGD was estimated to be $31 \%$ and $67 \%$ in severe and mild-to-moderate symptomatic patients, respectively [46].

Most importantly, their included studies adopted widely different methods for diagnosis of OGD, varying from self-reporting [46, 49, 51, 53-55, 60-63], physician reporting $[55,60]$, online questionnaires $[51,55$, 58], the University of Pennsylvania Smell Identification Test (UPSIT) [55-57, 60, 62], British version of UPSIT [45], Quality of life tool (sQOD-NS) [47, 61], the "Sniffin Sticks" test [51, 55, 57], Subjective assessment using SNOT -22 [51, 57], the Italian version of SNOT-22 [51], the Connecticut Chemosensory Clinical Research Center test (CCCRC) [48, 55, 57], COVID-19 Anosmia Reporting Tool for Clinicians [57, 63], standardized chemosensitive tests with odorants [58], non-validated questionnaires [58], butanol threshold assessment [48], case notes review (explicitly asked) [51], interviewing [51, 55, 62], history and physical examination $[49,54]$ and Smartphone based apps $[55,63]$. Several articles did not report the method of OGD diagnosis among the included study $[50,52,59]$.

Additional information of these studies is provided in Table 3.

\section{Studies on Guillen-Barré syndrome}

A total of 5 systematic reviews were conducted on Guillen-Barré Syndrome (GBS) and reporting data from case series, case reports and one cross-sectional study. Three of these studies were conducted in Europe [64-66] one in Bangladesh [67] and one in Chile [68]. Only one study conducted meta-analysis [67]. Two of these systematic reviews also conducted a quality assessment for including the studies $[67,68]$. The population of these studies consisted of COVID-19 patients, either with or without laboratory confirmed diagnosis, which showed GBS variants and subtypes manifestations. All of the included studies suggested a strong association between
COVID-19-associated GBS to the classic GBS. One of the studies drew attention to the fact that the prognosis of COVID-19-associated GBS patients seems to worsen by increasing of age [66]. Additional data are provided in Table 4.

It is note-worthy that another systematic review had been conducted on the GBS and COVID-19, but it investigated how COVID-19 can affect previously diagnosed GBS patients. Hence, it was excluded from our study [69].

\section{Studies on sporadic types of neurological manifestations}

Some studies reported sporadic neurological manifestations in COVID-19 patients; including two studies specifically on oral findings which reported dysgeusia [70, 71] and oral mucosal lesions, [71] in COVID-19 patients. Two studies were conducted on ocular manifestations; one study investigated the effects of prone positioning on ocular complications in COVID-19 patients in the critical care ward and reported that ocular surface disease, acute angle closure, ischemic optic neuropathy, orbital compartment syndrome and vascular occlusions are likely to occur in these patients [72]. The other study stated that ocular pain, discharge, redness and follicular conjunctivitis can arise from COVID-19 infection [73].

Auditory signs and symptoms was the main focus in one study; according to which in COVID-19-positive patients, hearing loss, tinnitus, and vertigo have rarely been reported [74].

ENT (Ear Nose Throat) manifestations were reported in one study that stated sore throat and headache as the most common ENT involvements in COVID-19 infection, while pharyngeal erythema, nasal congestion, rhinorrhea, upper respiratory tract infection, and tonsil enlargement were also reported with limited prevalence [75]. Furthermore, one study which aimed to assess the association between COVID-19 and encephalitis reported the occurrence of this complication in severe cases of infection and suggesting that COVID-19 virus can be considered as a neuropathogen with the ability to attack the nervous system regardless of respiratory symptoms [76]. At last, intracranial hemorrhage (IHC) was the subject in another systematic review. This study suggested that IHC is relatively uncommon among COVID19 patients, but has a correlation with higher mortality rates [77].

Quality assessment was not conducted due the limited number of these studies.

\section{Discussion}

The overall results of this umbrella review, which was conducted on 66 systematic reviews, demonstrated that neurological involvements are greatly common among 


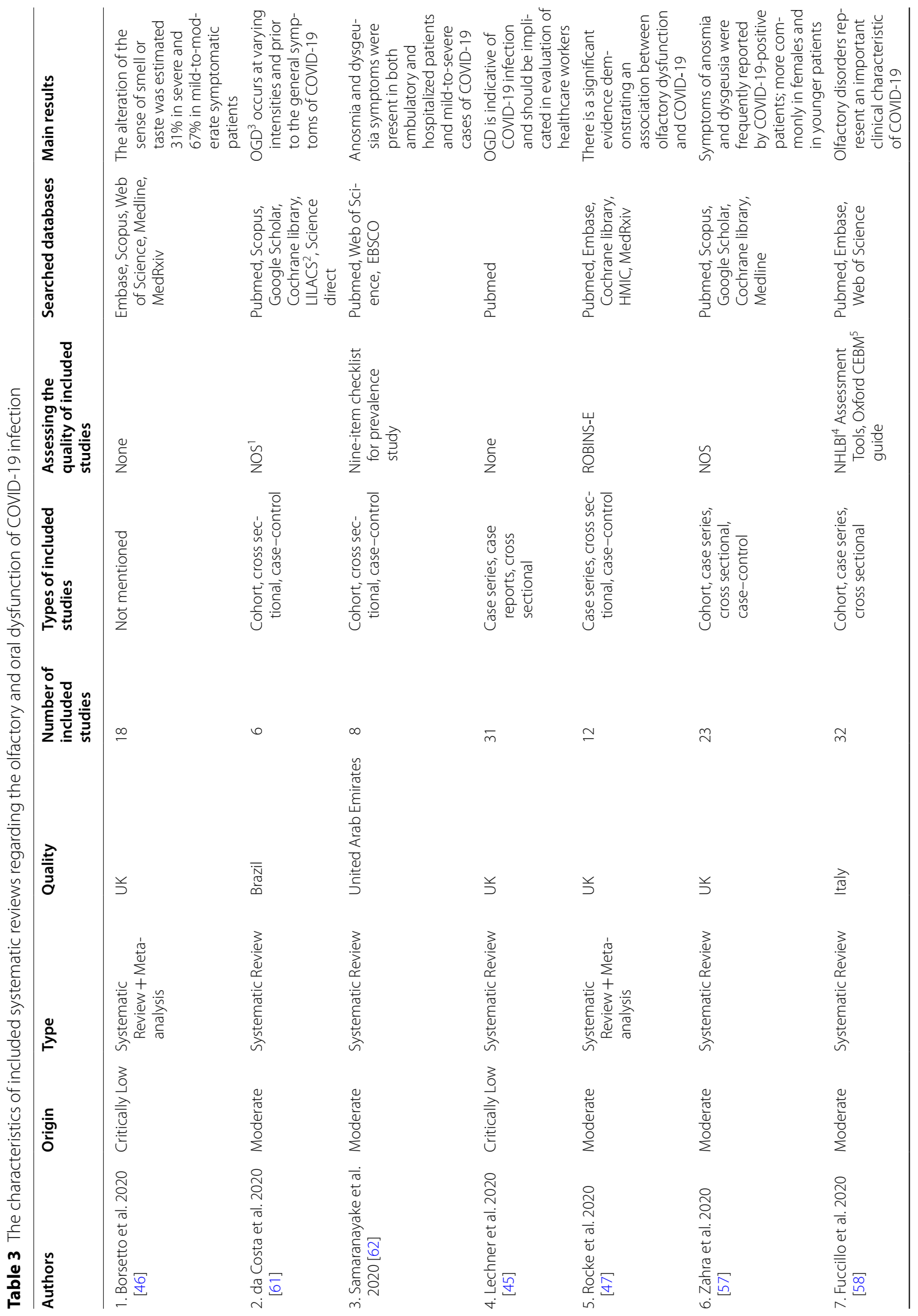




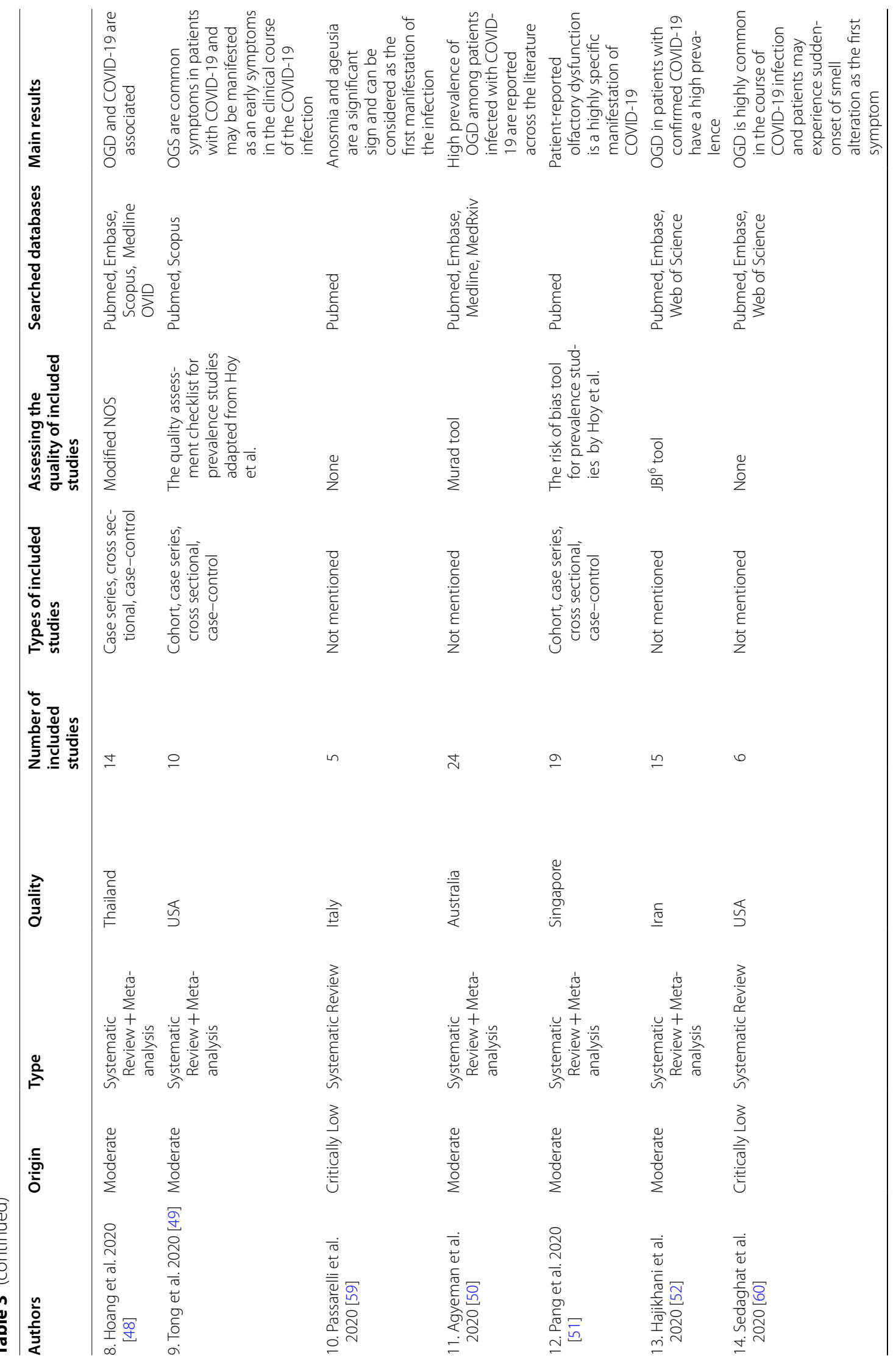




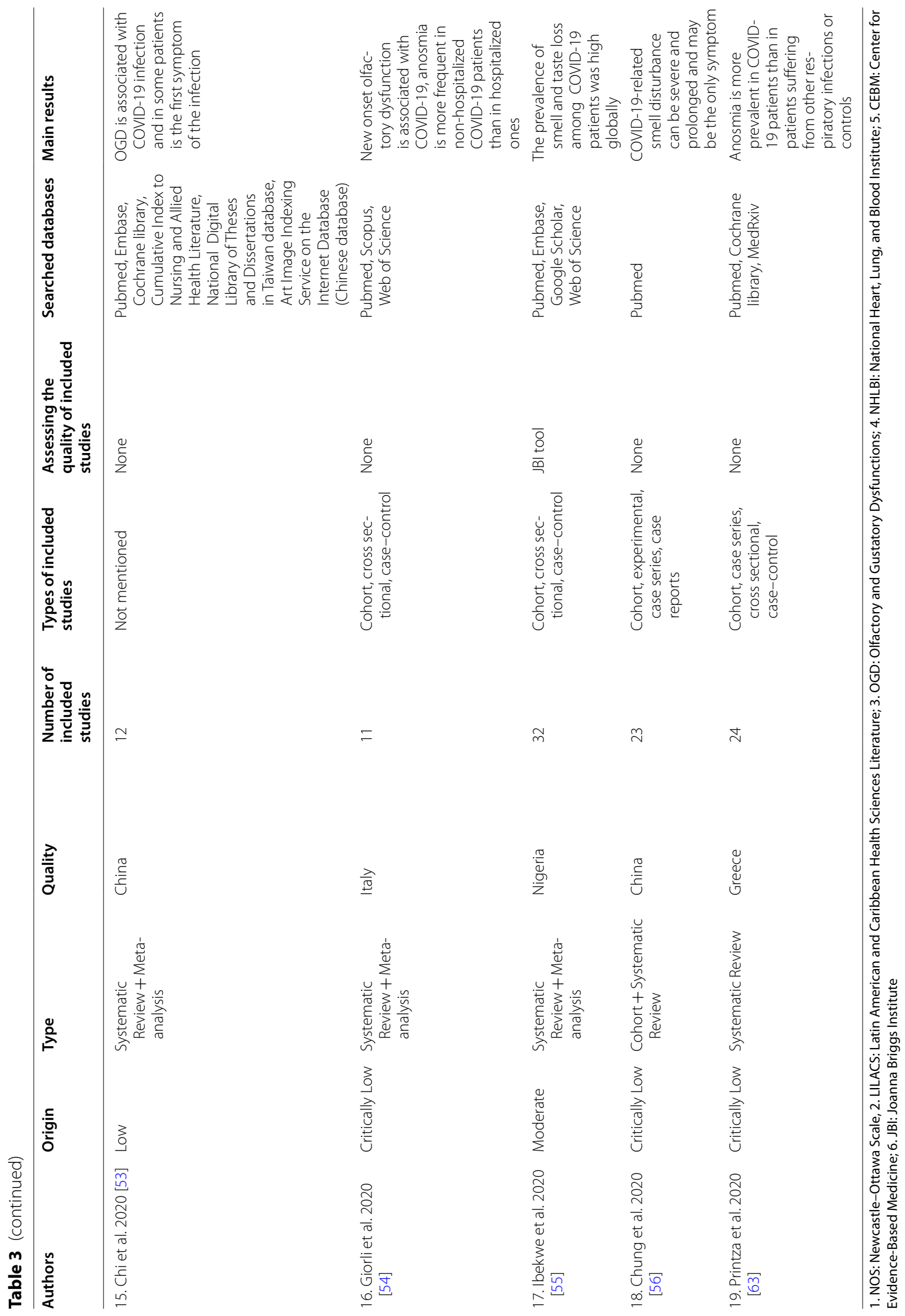




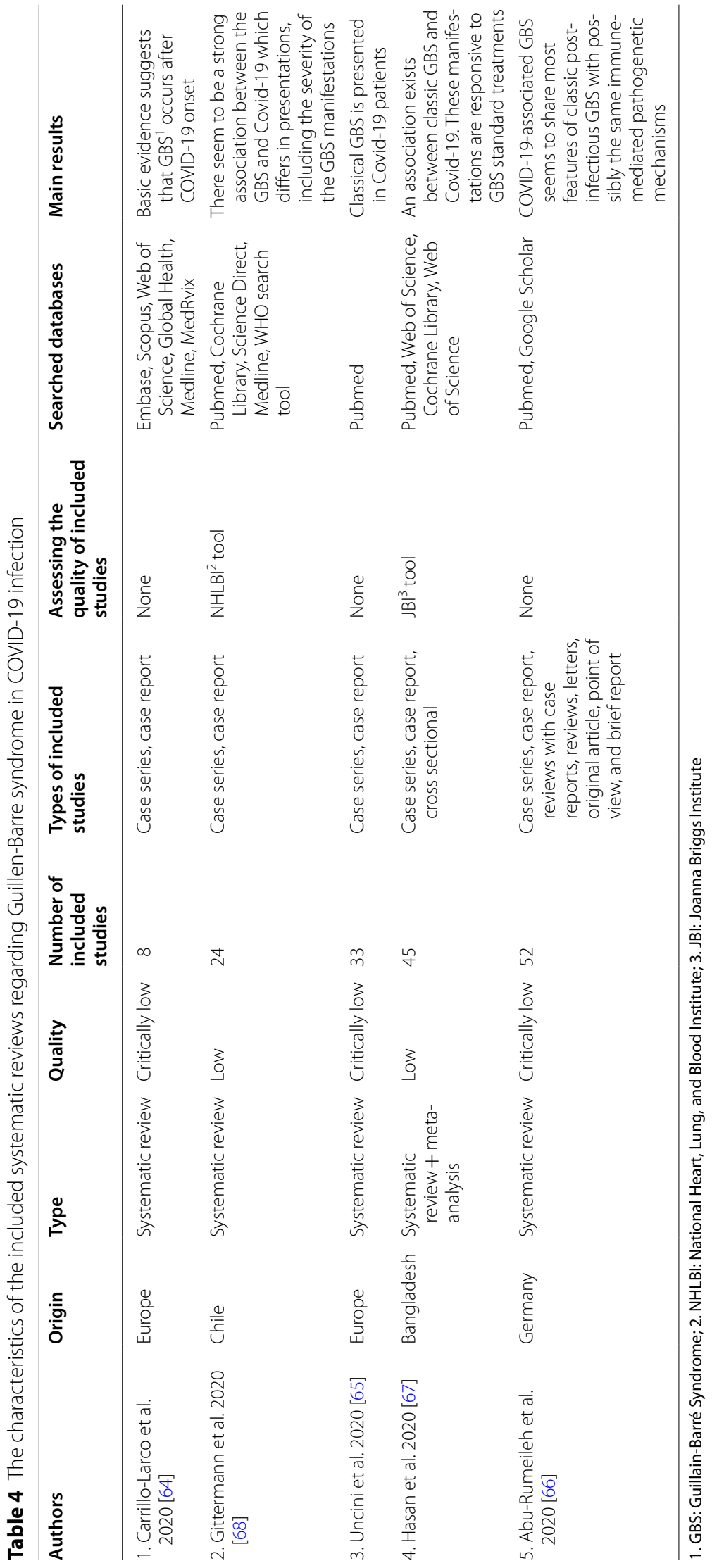


COVID-19 patients with many different general, specific and sporadic manifestations.

The majority of the systematic reviews seemed to be low on methodological quality aspect. This fact can be justified by the outburst of the infection and an urgent need to access some evidence for clinical decisions and policy-making [78]. The results of the methodological assessment of our work is reminiscent of a previous study which was conducted to evaluate the quality of 49 systematic reviews regarding Severe Acute Respiratory Syndrome (SARS) and Middle East Respiratory Syndrome (MERS). This study indicated that the most systematic reviews regarding the coronavirus do not have satisfactory methodological quality [79].

Headache, as a general manifestation, was mentioned most commonly by studies. The characteristics of this headache are described as pressing, worsened by physical activities or head movements [80]. In another study, this headache was described to have a pulsating, pressing, and stabbing quality [81]. Different patterns of involvement are described including mostly holocranial [80, 82, 83], hemicranial or occipital [80] or bilateral and frontal [83]. Moreover, individuals with a migraine history are predisposed to have an earlier, longer and more severe headaches in comparison with migraine-free patients [83]. Preexisting primary headache was significantly related to the higher frequency of headache caused by COVID-19 infection [82], while one study mentioned that majority of its study population did not have a history of prior headaches [84]. Limited studies have addressed the associated risk factors. In one study, anosmia, myalgia, female sex and fever were reported as independent factors leading to a higher odds of headache in COVID-19 patients [85].

Regarding the sporadic manifestation of the disease, in addition to the conditions which were priorly mentioned, several neurological manifestations have been linked to the SARS-CoV-2; including seizures [86, 87], demyelination [88] and encephalopathies [87] and meningitis [89]. Many different types of viral infections can lead to such presentations, which makes it impossible to settle on the fact that COVID-19 infection is directly leading to these clinical signs and symptoms. For instance, both acute symptomatic seizures and late unprovoked seizures are reported in almost all types of acute central nervous system viral infections [90]. Another example is applied to meningitis which has been presented in multiple viral infections including herpes simplex virus and varicella zoster virus [91].

Several limitations may have influenced the obtained results. To begin with, the population of studies is mostly locally selected with limited number of patients, restricting the manifestations of the disease to a specific age or race. This factor makes it impossible to generalized the results of studies to a global scope.

Another source of error can be stated as a bounded literature due to the novelty of the virus which can generate problems like limited knowledge on the long-term effects of the disease, associated risk factors in patients and how they affect the overall neurological process and the association between the severity of the infection and how it can cause different levels of neurologic involvement. In addition, the relationship between the type of the treatment and the occurrence of neurological manifestations has not been addressed by many studies in the current literature.

A major source of unreliability was heterogeneity among diagnostic methods in different manifestations; for instance, anosmia was diagnosed mostly by self-reporting, but other methods of diagnosis were also mentioned among studies. In addition, many of the studies did not specify the stage of severity of the COVID-19 infection, which can greatly affect the type of the signs and symptoms that follow the infection.

Finally, the search strategy was designed using many keywords in several databases to ensure that all the related articles were included but considering the high rate in which the COVID-19 articles are being published, some sources of data might be missed.

\section{Conclusions}

In conclusion, this study shows that neurological manifestations, most commonly general ones like headache and olfactory involvements, are an important aspect of the COVID-19 infection and the possibility of their occurrence should be considered in all infected patients. Therefore, our study underlines that all the COVID-19 patients should be carefully assessed and reassessed for detecting any neurological signs and symptoms. Considering how limited is known on the long-term effects of the neurologic involvement following this novel virus, continuous follow-up of infected patients is strongly suggested.

\section{Abbreviations}

COVID-19: Coronavirus disease 2019; AMSTAR-2: Assessment of Multiple Systematic Reviews-2; GBS: Guillen-Barré syndrome; PRISMA: Preferred Reporting Items for Systematic Reviews and Meta-analysis; URTI: Upper respiratory tract infection; IHC: Intracranial hemorrhage; SARS: Severe Acute Respiratory Syndrome; MERS: Middle East Respiratory Syndrome.

\section{Supplementary Information}

The online version contains supplementary material available at https://doi. org/10.1186/s41983-021-00366-5.

Additional file 1. AMSTAR 2: a critical appraisal tool for systematic reviews that include randomised or nonrandomised studies of healthcare interventions, or both. 


\section{Acknowledgements \\ None.}

\section{Authors' contributions}

We, hereby, confirm that all the authors have read and approved the manuscript final version. SSV: project administration, methodology, recourses, visualization, writing, finalizing. AA: supervision; recourses; validation, editing DR: writing, editing, review, finalizing. ESH: validation, review, finalizing. FT: conceptualization, data curation, methodology, investigation, original draft, writing, finalizing. All authors read and approved the final manuscript.

\section{Funding}

This study received no funding from any type of organization.

\section{Availability of data and materials}

All the data are available upon reasonable request.

\section{Declarations}

\section{Ethics approval and consent to participate}

The research protocol was approved and supported by Tabriz University of Medical Sciences (Project Number: 66714). This study was conducted on already published materials with no direct connection to any patients, therefore obtaining patient consent is not applicable.

\section{Consent for publication}

Not applicable.

\section{Competing interests}

The authors declare that they have no competing interests.

\section{Author details}

${ }^{1}$ Emergency Medicine Research Team, Emergency Department, Tabriz University of Medical Sciences, Tabriz, Iran. ${ }^{2}$ Student Research Committee, Tabriz University of Medical Sciences, Tabriz, Iran. ${ }^{3}$ Neurosciences Research Center, Neurology Department, Tabriz University of Medical Sciences, Tabriz, Iran.

Received: 9 June 2021 Accepted: 6 August 2021

Published online: 28 August 2021

\section{References}

1. Huang C, Wang Y, Li X, Ren L, Zhao J, Hu Y, Zhang L, Fan G, Xu J, Gu X, et al. Clinical features of patients infected with 2019 novel coronavirus in Wuhan, China. Lancet (London, England). 2020;395(10223):497-506.

2. Zaim S, Chong JH, Sankaranarayanan V, Harky A. COVID-19 and multiorgan response. Curr Prob Cardiol. 2020:45(8):100618.

3. Wu T, Zuo Z, Kang S, Jiang L, Luo X, Xia Z, Liu J, Xiao X, Ye M, Deng M. Multi-organ dysfunction in patients with COVID-19: a systematic review and meta-analysis. Aging Dis. 2020;11(4):874.

4. Mao L, Jin H, Wang M, Hu Y, Chen S, He Q, Chang J, Hong C, Zhou Y, Wang $D$, et al. Neurologic manifestations of hospitalized patients with coronavirus disease 2019 in Wuhan, China. JAMA Neurol. 2020;77(6):683-90.

5. Werner C, Scullen T, Mathkour M, Zeoli T, Beighley A, Kilgore MD, Carr C, Zweifler RM, Aysenne A, Maulucci CM, et al. Neurological impact of coronavirus disease of 2019: practical considerations for the neuroscience community. World Neurosurg. 2020;139:344-54.

6. Padda I, Khehra N, Jaferi U, Parmar MS. The neurological complexities and prognosis of COVID-19. SN Compr Clin Med 2020:1-12.

7. Smith V, Devane D, Begley CM, Clarke M. Methodology in conducting a systematic review of systematic reviews of healthcare interventions. BMC Med Res Methodol. 2011;11(1):15.

8. Schultz A, Goertzen L, Rothney J, Wener P, Enns J, Halas G, Katz A. A scoping approach to systematically review published reviews: adaptations and recommendations. Res Syn Methods. 2018;9(1):116-23.

9. Knobloch K, Yoon U, Vogt PM. Preferred reporting items for systematic reviews and meta-analyses (PRISMA) statement and publication bias. $J$ Cranio-Maxillofacial Surg. 2011;39(2):91-2.
10. Shea BJ, Reeves BC, Wells G, Thuku M, Hamel C, Moran J, Moher D, Tugwell P, Welch V, Kristjansson E. AMSTAR 2: a critical appraisal tool for systematic reviews that include randomised or non-randomised studies of healthcare interventions, or both. BMJ. 2017;358:j4008.

11. Abdullahi A, Candan SA, Abba MA, Bello AH, Alshehri MA, Afamefuna Victor E, Umar NA, Kundakci B. Neurological and musculoskeletal features of COVID-19: a systematic review and meta-analysis. Front Neurol. 2020;11:687.

12. Chua TH, Xu Z, King NKK. Neurological manifestations in COVID-19: a systematic review and meta-analysis. Brain Inj. 2020;34(12):1549-68.

13. Collantes MEV, Espiritu Al, Sy MCC, Anlacan VMM, Jamora RDG. Neurological manifestations in COVID-19 infection: a systematic review and meta-analysis. Can J Neurol Sci 2020:1-11.

14. Favas T, Dev P, Chaurasia RN, Chakravarty K, Mishra R, Joshi D, Mishra VN, Kumar A, Singh VK, Pandey M. Neurological manifestations of COVID-19: a systematic review and meta-analysis of proportions. Neurol Sci 2020:1-34.

15. MadaniNeishaboori A, Moshrefiaraghi D, Mohamed Ali K, Toloui A, Yousefifard M, Hosseini M. Central nervous system complications in COVID-19 patients; a systematic review and meta-analysis based on current evidence. Arch Acad Emerg Med. 2020;8(1):e62-e62.

16. Pinzon RT, Wijaya VO, Buana RB, Al Jody A, Nunsio PN. Neurologic characteristics in coronavirus disease 2019 (COVID-19): a systematic review and meta-analysis. Front Neurol. 2020;11:565.

17. Tsai S-T, Lu M-K, San S, Tsai C-H. The neurologic manifestations of coronavirus disease 2019 pandemic: a systemic review. Front Neurol. 2020;11:498.

18. Wang L, Shen Y, Li M, Chuang H, Ye Y, Zhao H, Wang H. Clinical manifestations and evidence of neurological involvement in 2019 novel coronavirus SARS-CoV-2: a systematic review and meta-analysis. J Neurol 2020:1-13.

19. Cagnazzo F, Arquizan C, Derraz I, Dargazanli C, Lefevre P-H, Riquelme C, Gaillard N, Mourand I, Gascou G, Bonafe A. Neurological manifestations of patients infected with the SARS-CoV-2: a systematic review of the literature. J Neurol 2020:1-10.

20. Chen X, Laurent S, Onur OA, Kleineberg NN, Fink GR, Schweitzer F, Warnke C. A systematic review of neurological symptoms and complications of COVID-19. J Neurol 2020:1-11.

21. Di Carlo DT, Montemurro N, Petrella G, Siciliano G, Ceravolo R, Perrini P. Exploring the clinical association between neurological symptoms and COVID-19 pandemic outbreak: a systematic review of current literature. J Neurol 2020:1-9.

22. Orrù G, Conversano C, Malloggi E, Francesconi F, Ciacchini R, Gemignani A. Neurological complications of COVID-19 and possible neuroinvasion pathways: a systematic review. Int J Environ Res Public Health. 2020;17(18):6688.

23. Romoli M, Jelcic I, Bernard-Valnet R, García Azorín D, Mancinelli L, Akhvlediani T, Monaco S, Taba P, Sellner J. Infectious disease panel of the European Academy of $\mathrm{N}$ : a systematic review of neurological manifestations of SARS-CoV-2 infection: the devil is hidden in the details. Eur J Neurol. 2020;27(9):1712-26.

24. Scoppettuolo P, Borrelli S, Naeije G. Neurological involvement in SARSCoV-2 infection: a clinical systematic review. Brain, Behav, ImmunHealth 2020:100094

25. Whittaker A, Anson M, Harky A. Neurological Manifestations of COVID-19: a systematic review and current update. Acta Neurol Scand. 2020;142(1):14-22.

26. Asadi-Pooya AA, Simani L. Central nervous system manifestations of COVID-19: a systematic review. J Neurol Sci 2020:116832.

27. Taherifard E, Taherifard E. Neurological complications of COVID-19: a systematic review. Neurol Res. 2020;42(11):905-12.

28. Nepal G, Rehrig JH, Shrestha GS, Shing YK, Yadav JK, Ojha R, Pokhrel G, Tu ZL, Huang DY. Neurological manifestations of COVID-19: a systematic review. Crit Care. 2020;24(1):1-11.

29. Munhoz RP, Pedroso JL, Nascimento FA, de Almeida SM, Barsottini OGP, Cardoso FEC, Teive HAG. Neurological complications in patients with SARS-CoV-2 infection: a systematic review. Arq Neuropsiquiatr. 2020:78(5):290-300.

30. Ibrahim W. Neurological manifestations in coronavirus disease 2019 (COVID-19) patients: a systematic review of literature. CNS Spectrums $2020: 1-34$ 
31. Ghannam M, Alshaer Q, Al-Chalabi M, Zakarna L, Robertson J, Manousakis G. Neurological involvement of coronavirus disease 2019: a systematic review. J Neurol. 2020;267(11):3135-53.

32. Lee KW, Yusof Khan AHK, Ching SM, Chia PK, Loh WC, Abdul Rashid AMi, Baharin J, Inche Mat LN, Wan Sulaiman WA, Devaraj NK et al. Stroke and novel coronavirus infection in humans: a systematic review and metaanalysis. Front Neurol 2020, 11(1196).

33. Fridman S, Bres Bullrich M, Jimenez-Ruiz A, Costantini P, Shah P, Just C, Vela-Duarte D, Linfante I, Sharifi-Razavi A, Karimi N, et al. Stroke risk, phenotypes, and death in COVID-19. Syst Rev Newly Rep Cases. 2020;95(24):e3373-85.

34. Katsanos AH, Palaiodimou L, Zand R, Yaghi S, Kamel H, Navi BB, Turc G, Romoli M, Sharma VK, Mavridis D, et al. The impact of SARS-CoV-2 on stroke epidemiology and care: a meta-analysis. Ann Neurol. 2021;89(2):380-8.

35. Yamakawa M, Kuno T, Mikami T, Takagi H, Gronseth G. Clinical characteristics of stroke with COVID-19: a systematic review and meta-analysis. J Stroke Cerebrovasc Dis. 2020;29(12):105288.

36. Nannoni S, de Groot R, Bell S, Markus HS. Stroke in COVID-19: a systematic review and meta-analysis. Int J Stroke: Off J Int Stroke Soc. 2021;16(2):137-49.

37. Tan Y-K, Goh C, Leow AS, Tambyah PA, Ang A, Yap E-S, Tu T-M, Sharma VK, Yeo LL, Chan BP. COVID-19 and ischemic stroke: a systematic review and meta-summary of the literature. J Thromb Thrombolysis. 2020;50(3):587-95.

38. Siepmann T, Sedghi A, Simon E, Winzer S, Barlinn J, de With K, Mirow L, Wolz M, Gruenewald T, Schroettner P, et al. Increased risk of acute stroke among patients with severe COVID-19: a multicenter study and metaanalysis. Eur J Neurol. 2021;28(1):238-47.

39. Szegedi I, Orbán-Kálmándi R, Csiba L, Bagoly Z. Stroke as a potential complication of COVID-19-associated coagulopathy: a narrative and systematic review of the literature. J Clin Med. 2020;9(10):3137.

40. Wijeratne T, Sales C, Karimi L, Crewther SG. Acute ischemic stroke in COVID-19: a case-based systematic review. Front Neurol 2020, 11(1031).

41. Fatima N, Saqqur M, Qamar F, Shaukat S, Shuaib A. Impact of COVID-19 on neurological manifestations: an overview of stroke presentation in pandemic. Neurol Sci. 2020;41(10):2675-9.

42. Valencia-Enciso N, Ortiz-Pereira M, Zafra-Sierra MP, Espinel-Gómez L, Bayona H. Time of stroke onset in Coronavirus disease 2019 patients around the globe: a systematic review and analysis: Running title: Stroke onset in COVID-19: systematic review. J Stroke Cerebrovascu Dis 2020:105325.

43. Fraiman P, Godeiro Junior C, Moro E, Cavallieri F, Zedde M. COVID-19 and cerebrovascular diseases: a systematic review and perspectives for stroke management. Front Neurol 2020, 11(1153)

44. Bhatia R, Pedapati R, Komakula S, Srivastava MVP, Vishnubhatla S, Khurana D. Stroke in coronavirus disease 2019: a systematic review. J Stroke. 2020;22(3):324-35.

45. Lechner M, Chandrasekharan D, Jumani K, Liu J, Gane S, Lund VJ, Philpott C, Jayaraj S. Anosmia as a presenting symptom of SARS-CoV-2 infection in healthcare workers-a systematic review of the literature, case series, and recommendations for clinical assessment and management. Rhinology. 2020;58(4):394-9.

46. Borsetto D, Hopkins C, Philips V, Obholzer R, Tirelli G, Polesel J, BoscoloRizzo P. Self-reported alteration of sense of smell or taste in patients with COVID-19: a systematic review and meta-analysis on 3563 patients. Rhinology. 2020;58(5):430-6

47. Rocke J, Hopkins C, Philpott C, Kumar N. Is loss of sense of smell a diagnostic marker in COVID-19: a systematic review and meta-analysis. Clin Otolaryngol. 2020;45(6):914-22.

48. Hoang MP, Kanjanaumporn J, Aeumjaturapat S, Chusakul S, Seresirikachorn K, Snidvongs K. Olfactory and gustatory dysfunctions in COVID-19 patients: a systematic review and meta-analysis. Asian Pac J Allergy Immunol. 2020;38(3):162-9.

49. Tong JY, Wong A, Zhu D, Fastenberg JH, Tham T. The prevalence of olfactory and gustatory dysfunction in COVID-19 patients: a systematic review and meta-analysis. Otolaryngol Head Neck Surg 2020:0194599820926473.

50. Agyeman AA, Chin KL, Landersdorfer CB, Liew D, Ofori-Asenso R. Smell and taste dysfunction in patients with COVID-19: a systematic review and meta-analysis. Mayo Clin Proc. 2020;95(8):1621-31.
51. Pang KW, Chee J, Subramaniam S, Ng CL. Frequency and clinical utility of olfactory dysfunction in COVID-19: a systematic review and meta-analysis. Curr Allergy Asthma Rep. 2020;20(12):1-17.

52. Hajikhani B, Calcagno T, Nasiri MJ, Jamshidi P, Dadashi M, Goudarzi M, Eshraghi AA, Mirsaeidi M. Olfactory and gustatory dysfunction in COVID19 patients: a meta-analysis study. Physiol Rep. 2020;8(18):e14578.

53. Chi H, Chiu N-C, Peng C-C, Lin C-H, Tai Y-L, Lee M-D, Cheng Y-J, Tan BF, Lin C-Y. One-seventh of patients with COVID-19 had olfactory and gustatory abnormalities as their initial symptoms: a systematic review and metaanalysis. Life. 2020;10(9):158.

54. Giorli A, Ferretti F, Biagini C, Salerni L, Bindi I, Dasgupta S, Pozza A, Gualtier G, Gusinu R, Coluccia A. A literature systematic review with meta-analysis of symptoms prevalence in covid-19: the relevance of olfactory symptoms in infection not requiring hospitalization. Curr Treat Options Neurol. 2020;22(10):1-14

55. Ibekwe TS, Fasunla AJ, Orimadegun AE. Systematic review and metaanalysis of smell and taste disorders in COVID-19. OTO open 2020, 4(3):2473974X20957975.

56. Chung TW-H, Sridhar S, Zhang AJ, Chan K-H, Li H-L, Wong FK-C, Ng M-Y, Tsang RK-Y, Lee AC-Y, Fan Z. Olfactory dysfunction in coronavirus disease 2019 patients: observational cohort study and systematic review. In: Open Forum Infectious Diseases: 2020: Oxford University Press US; 2020: ofaa199.

57. Zahra SA, Iddawela S, Pillai K, Choudhury RY, Harky A. Can symptoms of anosmia and dysgeusia be diagnostic for COVID-19? Brain Behav. 2020;10(11):e01839.

58. Fuccillo E, Saibene A, Canevini M, Felisati G. Olfactory disorders in coronavirus disease 2019 patients: a systematic literature review. J Laryngol Otol 2020:1-19.

59. Passarelli PC, Lopez MA, Bonaviri GM, Garcia-Godoy F, D'Addona A. Taste and smell as chemosensory dysfunctions in COVID-19 infection. Am J Dent. 2020;33(3):135-7.

60. Sedaghat AR, Gengler I, Speth MM. Olfactory dysfunction: a highly prevalent symptom of COVID-19 with public health significance. Otolaryngol-Head Neck Surg Off J Am Acad Otolaryngol-Head Neck Surg. 2020;163(1):12-5.

61. da Costa KVT, Carnaúba ATL, Rocha KW, da Andrade KCL, Ferreira SMS, Menezes PdL. Olfactory and taste disorders in COVID-19: a systematic review. Braz J Otorhinolaryngol. 2020;86(6):781-92.

62. Samaranayake LP, Fakhruddin KS, Panduwawala C. Sudden onset, acute loss of taste and smell in coronavirus disease 2019 (COVID-19): a systematic review. Acta Odontol Scand. 2020;78(6):467-73.

63. Printza A, Constantinidis J. The role of self-reported smell and taste disorders in suspected COVID-19. Eur Arch Otorhinolaryngol. 2020;277(9):2625-30.

64. Carrillo-Larco RM, Altez-Fernandez C, Ravaglia S, Vizcarra JA. COVID-19 and Guillain-Barre syndrome: a systematic review of case reports. Wellcome Open Res. 2020;5(107):107.

65. Uncini A, Vallat J-M, Jacobs BC. Guillain-Barré syndrome in SARS-CoV-2 infection: an instant systematic review of the first six months of pandemic. J Neurol Neurosurg Psychiatry. 2020;91(10):1105-10.

66. Abu-Rumeileh S, Abdelhak A, Foschi M, Tumani H, Otto M. Guillain-Barré syndrome spectrum associated with COVID-19: an up-to-date systematic review of 73 cases. J Neurol 2020:1-38.

67. Hasan I, Saif-Ur-Rahman KM, Hayat S, Papri N, Jahan I, Azam R, Ara G, Islam Z. Guillain-Barré syndrome associated with SARS-CoV-2 infection: a systematic review and individual participant data meta-analysis. J Peripher Nerv Syst. 2020;25(4):335-43.

68. Trujillo Gittermann LM, Valenzuela Feris SN, von Oetinger GA. Relation between COVID-19 and Guillain-Barré syndrome in adults. Systematic review. Neurologia (Engl Ed). 2020;35(9):646-54

69. De Sanctis P, Doneddu PE, Viganò L, Selmi C, Nobile-Orazio E. GuillainBarré syndrome associated with SARS-CoV-2 infection. A systematic review. Eur J Neurol. 2020;27(11):2361-70.

70. Aziz M, Perisetti A, Lee-Smith WM, Gajendran M, Bansal P, Goyal H. Taste changes (dysgeusia) in COVID-19: a systematic review and meta-analysis. Gastroenterology. 2020:159(3):1132-3.

71. Amorim Dos Santos J, Normando AGC, Carvalho da Silva RL, Acevedo AC, De Luca CG, Sugaya N, Santos-Silva AR, Guerra ENS. Oral manifestations in patients with COVID-19: a living systematic review. J Dental Res. 2021;100(2):141-54 
72. Sanghi P, Malik M, Hossain IT, Manzouri B. Ocular complications in the prone position in the critical care setting: the COVID-19 pandemic. J Intensive Care Med. 2021;36(3):361-72.

73. Aggarwal K, Agarwal A, Jaiswal N, Dahiya N, Ahuja A, Mahajan S, Tong L, Duggal M, Singh M, Agrawal R. Ocular surface manifestations of coronavirus disease 2019 (COVID-19): a systematic review and meta-analysis. PLoS ONE. 2020;15(11):e0241661.

74. Almufarrij I, Uus K, Munro KJ. Does coronavirus affect the audio-vestibular system? A rapid systematic review. Int J Audiol 2020:1-5.

75. El-Anwar MW, Elzayat S, Fouad YA. ENT manifestation in COVID-19 patients. Auris Nasus Larynx. 2020;47(4):559-64.

76. Khosraviani S, Paybast S, Emami A. Encephalitis as a rare manifestation of novel covid-19 disease, a para-infection or postinfection complication: a systematic review. Ro J Neurol. 2020; 19(3).

77. Cheruiyot I, Sehmi P, Ominde B, Bundi P, Mislani M, Ngure B, Olabu B, Ogeng'o JA. Intracranial hemorrhage in coronavirus disease 2019 (COVID-19) patients. Neurol Sci: Off J Italian Neurol Soc Italian Soc Clin Neurophysiol. 2021;42(1):25-33.

78. Dobler CC. Poor quality research and clinical practice during COVID-19. Breathe (Sheff). 2020;16(2):200112-200112.

79. Yu Y, Shi Q, Zheng P, Gao L, Li H, Tao P, Gu B, Wang D, Chen H. Assessment of the quality of systematic reviews on COVID-19: a comparative study of previous coronavirus outbreaks. J Med Virol. 2020;92(7):883-90.

80. Porta-Etessam J, Matías-Guiu JA, González-García N, Gómez Iglesias P, Santos-Bueso E, Arriola-Villalobos P, García-Azorín D, Matías-Guiu J. Spectrum of headaches associated with SARS-CoV-2 infection: study of healthcare professionals. Headache. 2020;60(8):1697-704.

81. Uygun Ö, Ertaş M, Ekizoğlu E, Bolay H, Özge A, Kocasoy Orhan E, Çağatay AA, Baykan B. Headache characteristics in COVID-19 pandemic-a survey study. J Headache Pain. 2020;21(1):121.

82. Magdy R, Hussein M, Ragaie C, Abdel-Hamid HM, Khallaf A, Rizk HI, Dahshan A. Characteristics of headache attributed to COVID-19 infection and predictors of its frequency and intensity: a cross sectional study. Cephalalgia. 2020;40(13):1422-31.

83. Membrilla JA, de Lorenzo I, Sastre M, Díaz de Teran J. Headache as a cardinal symptom of coronavirus disease 2019: a cross-sectional study. Headache. 2020;60(10):2176-91.
84. Toptan T, Aktan Ç, Başarı A, Bolay H. Case series of headache characteristics in COVID-19: headache can be an isolated symptom. Headache. 2020;60(8):1788-92.

85. Trigo J, García-Azorín D, Planchuelo-Gómez Á, Martínez-Pías E, Talavera B, Hernández-Pérez I, Valle-Peñacoba G, Simón-Campo P, de Lera M, Chavarría-Miranda A, et al. Factors associated with the presence of headache in hospitalized COVID-19 patients and impact on prognosis: a retrospective cohort study. J Headache Pain. 2020;21(1):94.

86. Asadi-Pooya AA, Simani L, Shahisavandi M, Barzegar Z. COVID-19, de novo seizures, and epilepsy: a systematic review. Neurol Sci: Off J Italian Neurol Soc Italian Soc Clin Neurophysiol. 2021;42(2):415-31.

87. Dorche MS, Huot P, Osherov M, Wen D, Saveriano A, Giacomini P, Antel JP, Mowla A. Neurological complications of coronavirus infection; a comparative review and lessons learned during the COVID-19 pandemic. J Neurol Sci 2020:117085.

88. Montalvan V, Lee J, Bueso T, De Toledo J, Rivas K. Neurological manifestations of COVID-19 and other coronavirus infections: a systematic review. Clin Neurol Neurosurg. 2020;194:105921.

89. Naz S, Hanif M, Haider MA, Ali MJ, Ahmed MU, Saleem S. Meningitis as an initial presentation of COVID-19: a case report. Front Public Health 2020, 8(474).

90. Misra UK, Tan CT, Kalita J. Viral encephalitis and epilepsy. Epilepsia. 2008;49(Suppl 6):13-8.

91. Granerod J, Ambrose HE, Davies NW, Clewley JP, Walsh AL, Morgan D, Cunningham R, Zuckerman M, Mutton KJ, Solomon T, et al. Causes of encephalitis and differences in their clinical presentations in England: a multicentre, population-based prospective study. Lancet Infect Dis. 2010;10(12):835-44.

\section{Publisher's Note}

Springer Nature remains neutral with regard to jurisdictional claims in published maps and institutional affiliations.

\section{Submit your manuscript to a SpringerOpen ${ }^{\circ}$ journal and benefit from:}

- Convenient online submission

- Rigorous peer review

- Open access: articles freely available online

- High visibility within the field

- Retaining the copyright to your article

Submit your next manuscript at $\boldsymbol{\nabla}$ springeropen.com 